\title{
Hesperetin attenuates silica-induced lung injury by reducing oxidative damage and inflammatory response
}

\author{
SHUXIAN LI ${ }^{1 *}$, LINLIN SHAO $^{2 *}$, JINGUO FANG $^{3}$, JUAN ZHANG $^{1}$, YANQIN CHEN $^{1}$, \\ ABREY J. YEO ${ }^{4}$, MARTIN F. LAVIN ${ }^{4}$, GONGCHANG YU $^{1}$ and HUA SHAO ${ }^{1}$ \\ ${ }^{1}$ Shandong Academy of Occupational Health and Occupational Medicine, Shandong First Medical University and \\ Shandong Academy of Medical Sciences, Jinan, Shandong 250062; ${ }^{2}$ Department of Neurology, \\ Shandong Provincial Hospital Affiliated to Shandong First Medical University, Jinan, Shandong 250021; \\ ${ }^{3}$ Primary Health Department, Linqing Health Bureau, Linqing, Shandong 252600, P.R. China; ${ }^{4}$ Centre \\ for Clinical Research, The University of Queensland, Brisbane, Queensland 4072, Australia
}

Received May 29, 2020; Accepted December 11, 2020

DOI: $10.3892 /$ etm.2021.9728

\begin{abstract}
Oxidative stress and the inflammatory response are two important mechanisms of silica-induced lung injury. Hesperetin (HSP) is a natural flavonoid compound that is found in citrus fruits and has been indicated to exhibit strong antioxidant and anti-inflammatory properties. The current study evaluated the protective effect of HSP on lung injury in rats exposed to silica. The results indicated that the degree of alveolitis and pulmonary fibrosis in the HSP-treated group was significantly decreased compared with the silica model group. The content of hydroxyproline (HYP) was also revealed to decrease overall in the HSP treated group compared with the silica model group, indicating that the degree of pulmonary fibrosis was decreased compared with the silica model group. The present study also demonstrated that HSP reduced oxidation levels of malondialdehyde (MDA) and increased the activities of antioxidant enzymes superoxide dismutase (SOD), catalase (CAT) and glutathione peroxidase (GSH-PX). Total antioxidant capacity (T-AOC) was also increased following HSP treatment, indicating that HSP can alleviate oxidative stress in the lung tissue of silica-exposed rats. In addition, HSP was revealed to inhibit the synthesis and secretion of fibrogenic factor TGF- $\beta 1$, reduce the production of pro-inflammatory cytokines IL-1 $\beta$, IL-4, TNF- $\alpha$ and increase
\end{abstract}

Correspondence to: Dr Gongchang Yu or Dr Hua Shao, Shandong Academy of Occupational Health and Occupational Medicine, Shandong First Medical University and Shandong Academy of Medical Sciences, 18877 Jingshi Road, Jinan, Shandong 250062, P.R. China

E-mail: 41164295@qq.com

E-mail: chinashaohua5888@163.com

${ }^{*}$ Contributed equally

Key words: silica, hesperetin, lung injury, fibrosis, oxidative stress, inflammatory response, rat the levels of anti-inflammatory factors IFN- $\gamma$ and IL-10. The current study demonstrated that HSP can effectively attenuate silica-induced lung injury by reducing oxidative damage and the inflammatory response.

\section{Introduction}

Silicosis is an interstitial pulmonary fibrosis disease that is caused by inhalation of crystalline silica and is characterized by inflammation and fibrosis of the lung $(1,2)$. Silicosis is the most common occupational disease in developing countries, has become a global threat to human health and caused wide public concern over recent years, with increasing incidence and prevalence (3). In China, there are $>20,000$ new cases of silicosis each year (4). Once silicosis occurs the damage is irreversible, and the condition may continue to progress even after the individual is removed from exposure to silica (5).

The crystalline silica, alpha quartz, is the major cause of silicosis. Inhaled silica particles are deposited in lung and distal airways and engulfed by alveolar macrophages. In turn, macrophages are activated, and these provoke the abundant generation of reactive oxygen species (ROS) and inflammatory cytokines (6). The oxygen-based free radicals generated from silica exposure are important initiators of the fibrotic process, and the persistent inflammation induced serves a key role in the pathogenesis of silica-induced diseases $(7,8)$. TGF- $\beta 1$ is a pivotal mediator of fibrosis and the TGF- $\beta 1$ signal is transduced through the activation of its down-stream effectors, the Smad proteins $(9,10)$. It has been previously demonstrated that TGF- $\beta 1$ was able to induce alveolar epithelial cells to undergo Epithelial to mesenchymal transition (EMT) in vivo and in vitro via Smad2 activation (11). Together, these factors stimulate the proliferation of lung fibroblasts, the production of collagen and subsequently the formation of fibrosis $(2,12-14)$. However, previous studies have demonstrated that antioxidants, including vitamins, carotenoids and tannins provide protection against oxidative damage, and the negative regulation of inflammatory cytokines and/or the inflammatory signaling pathway may attenuate the progression of some pulmonary diseases (15-18). 
At present, there is no effective treatment for silicosis. The conventional treatment used for patients is symptomatic treatment. If the symptoms are serious, glucocorticoids are used, and lung transplantation is the last treatment option available for pulmonary fibrosis (19). Recently, increasing attention has been paid to the anti-fibrotic effect of pirfenidone (PFD), which is one of two approved therapies for the treatment of idiopathic pulmonary fibrosis (IPF) (20). In 2014, PFD was approved for the treatment of the IPF by the U.S. Food and Drug Administration (6). However, PFD has not been widely used because of its side effects and high price (21). It is necessary to find more effective drugs for the treatment of silicosis.

According to the pathogenesis of silicosis, enhancing antioxidative and anti-inflammatory capacity may be a promising approach to preventing silica-induced lung injury and fibrosis (22). Currently, natural products present a promising approach for the treatment of a variety of acute and chronic inflammatory and fibrotic diseases (23). Hesperetin (HSP) is a natural flavonoid that exhibits a number of properties including anti-inflammatory, antioxidative, anti-bacterial anti-tumoral effects (24). HSP can target multiple cell proteins that inhibit tumor growth, including caspases, Bcl-2 and Bax-induced apoptosis, and is a promoter of cellular antioxidant defence-related enzyme activity (25). Furthermore, HSP has been demonstrated to exhibit beneficial effects in the treatment of hypertension, diabetes and dyslipidemia, and has become a promising drug candidate for the treatment of a cardiovascular diseases (26). HSP has also been reported to be a potential therapy for the treatment of inflammatory liver diseases via its anti-inflammatory effects (27).

To the best of our knowledge, there have been no studies performed that have investigated the effect of HSP on silica-induced lung injury. Therefore, the current study aimed to assess whether HSP exhibited protective effects against silica-induced lung injury and fibrosis by alleviating oxidative stress and inflammation.

\section{Materials and methods}

Animals and treatment. A total of 72 healthy male Wistar rats [specific pathogen-free grade (SPF); 180-200 g; 6-8 weeks old] were provided by Beijing Victoria Tong Lihua Experimental Animal Technology Co., Ltd. The rats were housed in SPF-grade laboratory conditions at $22 \pm 2^{\circ} \mathrm{C}$ with an average relative humidity of $40-70 \%$ and a $12 / 12 \mathrm{~h}$ light/dark cycle. All rats were kept in separate cages and had free access to water and standard laboratory food. According to animal ethics requirements (28), appropriate measures were taken using pain management protocols to reduce pain in the animals, and the relief of pain and distress received careful attention during the experiment.

Rats were randomly divided into 6 groups with 12 rats in each, and each group was divided into 2 time points (7 and 28 days). The groups were as follows: Negative control group, silica model group, PFD positive control group and $100,200,400 \mathrm{mg} / \mathrm{kg}$ HSP treatment groups. The $\mu \mathrm{m}$-sized silicon dioxide was prepared with normal saline as a $50 \mathrm{mg} / \mathrm{ml}$ silica suspension. All groups excluding for the negative control group were injected with $1 \mathrm{ml} 50 \mathrm{mg} / \mathrm{kg}$ silicon dioxide suspension into the lung once using a non-exposed tracheal intubation, and the rats in the negative control group were injected with the same volume of normal saline solution. After $24 \mathrm{~h}$, the clinical signs were examined, including hair, breath and weight, and the rats in the PFD positive control group and HSP treatment groups were given a daily intragastric administration of $100 \mathrm{mg} / \mathrm{kg}$ PFD (Beijing Kangdini Pharmaceutical Co., Ltd.) and 100, 200, 400 mg/kg HSP (Chengdu Kanghua Pharmaceutical Co., Ltd.) for 7 and 28 days. The rats in the negative control and silica model groups were treated with saline only. On day 7 and 28 following silica exposure, 6 rats in each group were euthanized with an overdose of $150 \mathrm{mg} / \mathrm{kg}$ sodium pentobarbital (Merck \& Co, Inc.) via intraperitoneal injection, and death in all rats was via observation of the cessation of respiration and palpation of the heartbeat. The lungs of each rat were harvested and used for histological examination and the determination of oxidative stress and inflammatory factors.

Histopathological examination of lung tissue. Lungs of rats were fixed in $4 \%$ paraformaldehyde solution at $4^{\circ} \mathrm{C}$ for $24 \mathrm{~h}$, embedded in paraffin and sectioned into $5 \mu \mathrm{m}$-thick slices. Subsequently, the tissue samples were stained with hematoxylin and eosin (H\&E; hematoxylin staining solution, 3-5 min; eosin staining solution, $5 \mathrm{~min}$; both room temperature) and Masson's trichrome (Weigert's iron hematoxylin solution, 5-10 min; ponceau fuchsin acid solution for 5-10 min; $1 \%$ phosphomolybdic acid aqueous solution for 3-5 min; aniline blue for $5 \mathrm{~min}$; immersion in $0.2 \%$ acetic acid aqueous solution for $1 \mathrm{~min}$; all at room temperature). Slides were then examined under a light microscope to assess the general morphology of the lung tissue. The degree of alveolitis and pulmonary fibrosis was evaluated according to the scoring system outlined in Szapiel et al (29). Alveolitis was graded using the following criteria: None (0), no alveolitis; mild (1+), thickening of the alveolar septum by a mononuclear cell infiltrate; moderate $(2+)$, a more widespread alveolitis; severe $(3+)$, a diffuse alveolitis. The extent of fibrosis was graded using the following criteria: None (0), no fibrosis; mild (1+), focal regions of fibrosis, alveolar architecture has some distortion; moderate $(2+)$, more extensive fibrosis and fibrotic still focal; severe $(3+)$, widespread fibrosis, confluent lesions with extensive derangement of parenchymal architecture.

Determination of hydroxyproline (HYP) content in lung tissue. As an important indicator of collagen level and the severity of fibrosis, the content of HYP in the lung tissue was assessed. The tissue was heated at a $95^{\circ} \mathrm{C}$ water bath for $30 \mathrm{~min}$ and HYP was measured using hydroxyproline assay kit as per the manufacturer's protocol (cat. no. A030-2-1; Nanjing Jiancheng Bioengineering Institute). For the control and standard samples, water and $5 \mu \mathrm{g} / \mathrm{ml}$ kit standard were used, respectively. Each sample was repeated three times. A spectrophotometer was used to measure the absorbance of each sample at $550 \mathrm{~nm}$.

Determination of oxidation indexes and inflammatory factors. Rat lung tissue was homogenized, centrifuged at $4^{\circ} \mathrm{C}$ at $12,000 \mathrm{x}$ g for $15 \mathrm{~min}$ and the supernatant was extracted. The levels of malondialdehyde (MDA), the activities of superoxide dismutase (SOD), glutathione peroxidase (GSH-PX), catalase (CAT) and total antioxidant capacity (T-AOC) in the homogenate 
were determined using commercial kits as per the manufacturer's instructions (Nanjing Jiancheng Bioengineering Institute). The MDA assay kit (cat. no. A003-1-2), the T-SOD assay kit (cat. no. A001-1-2), the GSH-PX assay kit (cat. no. A005-1-2), the CAT assay kit (cat. no. A007-1-1) and the T-AOC assay kit (cat. no. A015-1-2) were used for the detection of oxidation indexes. The levels of TGF- $\beta 1$, IL- $1 \beta$, IL- 4 , IL- 10 , TNF- $\alpha$ and IFN- $\gamma$ in the lung tissue homogenate of rats in each group were determined using ELISA as per the manufacturer's instructions (eBioscience; Thermo Fisher Scientific, Inc.). The TGF- $\beta 1$ Rat ELISA kit (cat. no. BMS623-3), the IL-1 $\beta$ Rat ELISA kit (cat. no. BMS630), the IL-4 Rat ELISA kit (cat. no. ERA29RB), the IL-10 Rat ELISA kit (cat. no. ERA23RB), the TNF- $\alpha$ Rat ELISA kit (cat. no. ERA56RB) and the IFN- $\gamma$ Rat ELISA kit (cat. no. BMS621) were used for the detection of inflammatory factors.

Statistical analysis. All data were presented as mean $\pm \mathrm{SD}$, and were analyzed using SPSS 22.0 software (IBM Corp.). Group comparisons were performed using a one-way ANOVA followed by Tukey test for normally distributed data and Kruskal-Wallis test and Dunn-Bonferroni post-hoc test for non-normally distributed data. $\mathrm{P}<0.05$ was considered to indicate a statistically significant difference.

\section{Results}

Rat phenotypes. Following exposure to silica, compared with the negative control group, the weight of the rats in the silica model group was considerably reduced, but this was statistically significant only on day $28(\mathrm{P}<0.05)$. However, the weights of the rats from the PFD and HSP treatment groups were markedly increased compared with the silica model group but there was no statistical difference ( $\mathrm{P}>0.05$; Fig. 1).

Histopathological examination. As presented in Fig. 2, after 7 days of silica exposure, histopathological examination of rat lungs showed that lung tissues from the negative control group were morphologically normal and the alveolar structure was intact with a few inflammatory cells that had been induced by saline. Conversely, tissue structure from rats in the silica model and the PFD and HSP treatment groups were disrupted. The walls of the alveoli and the alveolar septum were thickened, and severe inflammatory cell infiltration was observed. The degree of inflammatory cell infiltration in the lungs of rats in each treatment group was reduced and the alveolar structure was more intact compared with those in the silica model group. As presented in Fig. 3, after 28 days of silica exposure, $H \& E$ staining demonstrated that rat lung tissues in the model group exhibited increased alveolar inflammation and fibroblast development, and the alveolar structure was further disrupted. The lung tissues from rats in the intervention groups showed improvement compared with those from the silica model group. Administration of PFD and HSP for 28 days ameliorated the inflammatory infiltration and the damaged structure in the lung tissue compared with the silica model group. Furthermore, alleviation of lung injury was observed following increasing doses of HSP. As presented in Fig. 4, Masson's trichrome stain revealed the alveolar walls were thickened with more collagen deposition revealed in rats

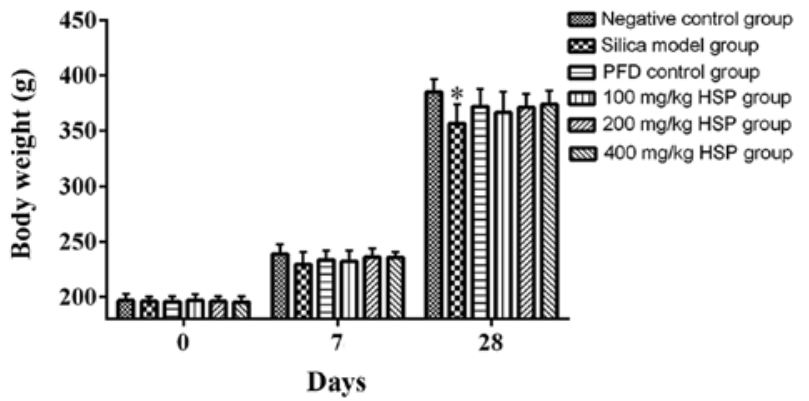

Figure 1. The effects of HSP treatment on the body weight of rats exposed to silica. ${ }^{*} \mathrm{P}<0.05$ vs. negative control group. HSP, hesperetin; PFD, pirfenidone.

from the silica model group compared with those in the negative control group on the 28th day. In lung tissues from rats in the PFD and HSP treatment groups, markedly less collagen deposition was observed compared with the silica model group. A decrease in the deposition of collagen in the lungs with increasing dosages of HSP was also observed.

Lung tissue alveolitis and fibrosis severity score. According to the method proposed by Szapiel et al (29), the degree of alveolitis and fibrosis in rat lung tissues with silica was evaluated. The alveolitis score of the silica model group was significantly higher compared with the negative control group $(\mathrm{P}<0.05)$. The alveolitis scores of the PFD positive control group, 100, 200 and $400 \mathrm{mg} / \mathrm{kg}$ HSP treatment groups were lower compared with the silica model group on the 7 and 28th day following treatment, but there was no statistical difference between the $100 \mathrm{mg} / \mathrm{kg}$ HSP treatment group and the silica model group on the 7 and 28th day ( $\mathrm{P}>0.05$; Fig. 5). The pulmonary fibrosis score of the silica model group on the 28th day was significantly higher compared with the negative control group $(\mathrm{P}<0.05)$. The pulmonary fibrosis scores of the PFD positive control group and 200 and $400 \mathrm{mg} / \mathrm{kg}$ HSP treatment groups on the 28th day were lower compared with the silica model group $(\mathrm{P}<0.05)$. The pulmonary fibrosis score of the $100 \mathrm{mg} / \mathrm{kg}$ HSP treatment group was lower compared with the model group, but there was no statistical difference $(\mathrm{P}>0.05$; Fig. 6$)$. In addition, numerous infiltrating inflammatory cells and inflammatory reactions in the lung tissues exposed to silica for 7 days have been reported, while in the lungs exposed to silica for 28 days, massive proliferation of collagen fibers and pulmonary fibrosis has been observed (30). Therefore, the pulmonary fibrosis score was only assessed on the 28th day in this experiment.

Effect of HSP on the content of HYP in rat lung tissue. The content of HYP in the lung tissue from rats in the silica model group was significantly higher compared with the negative control group $(\mathrm{P}<0.05)$ on the 7 and 28th day following treatment. Following PFD and HSP treatment, the content of HYP in the lungs of rats was lower compared with the silica model group on the 28th day $(\mathrm{P}<0.05$; Fig. 7$)$.

\section{Analysis of MDA level, SOD, CAT, GSH-Px and T-AOC activity in lung tissue \\ Effect of HSP on the level of MDA in lung tissue of silica exposed rats. On the 7 and 28th days after exposure, the level}




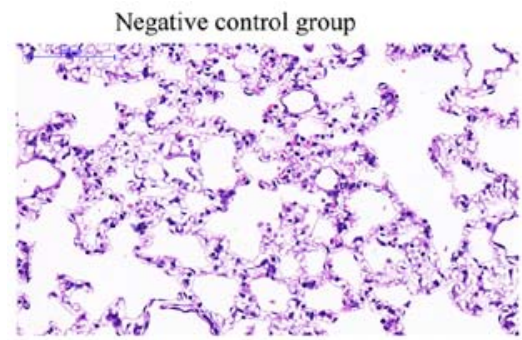

$100 \mathrm{mg} / \mathrm{kg}$ HSP treatment group

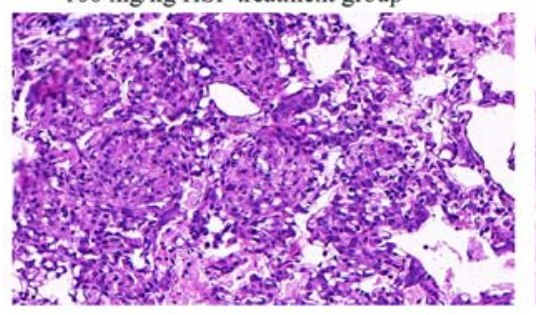

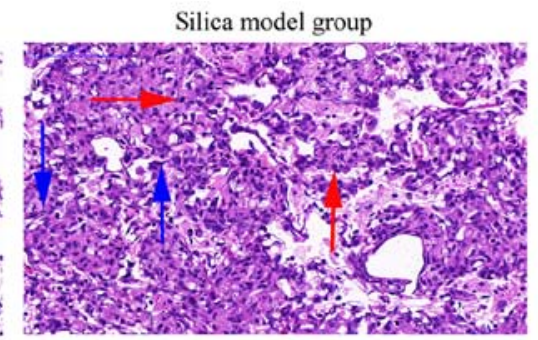

$200 \mathrm{mg} / \mathrm{kg}$ HSP treatment group

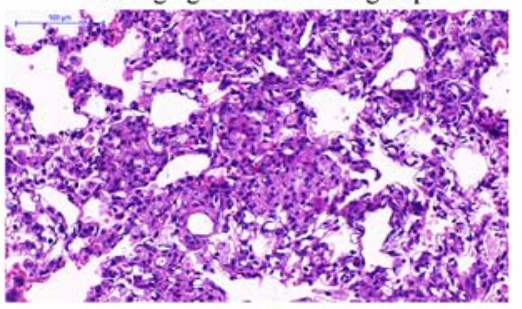

PFD positive control group

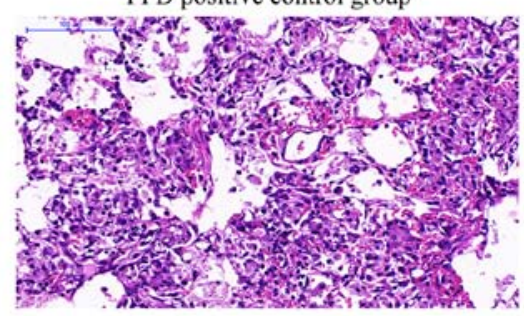

$400 \mathrm{mg} / \mathrm{kg}$ HSP treatment group

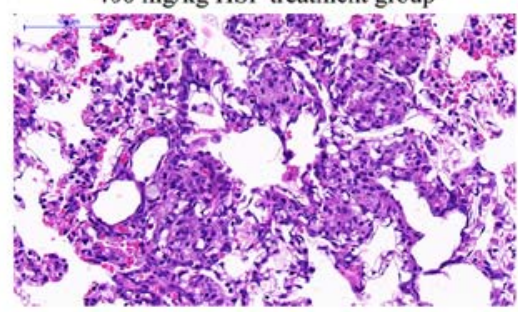

Figure 2. Hematoxylin and eosin staining of rat lung tissue on the 7th day (magnification, x200). The red arrows indicate inflammatory cells. Blue arrows indicate fibroblasts. HSP, hesperetin; PFD, pirfenidone.
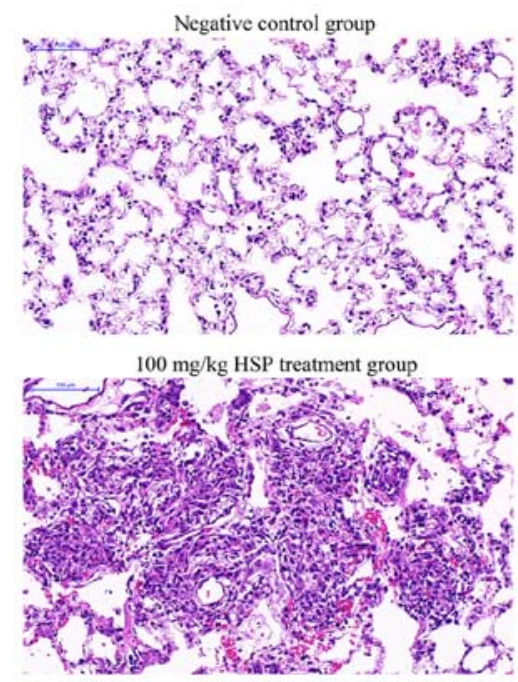
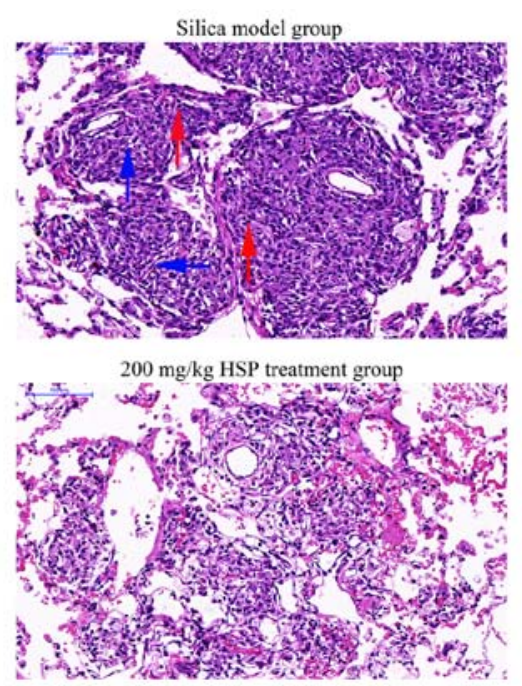
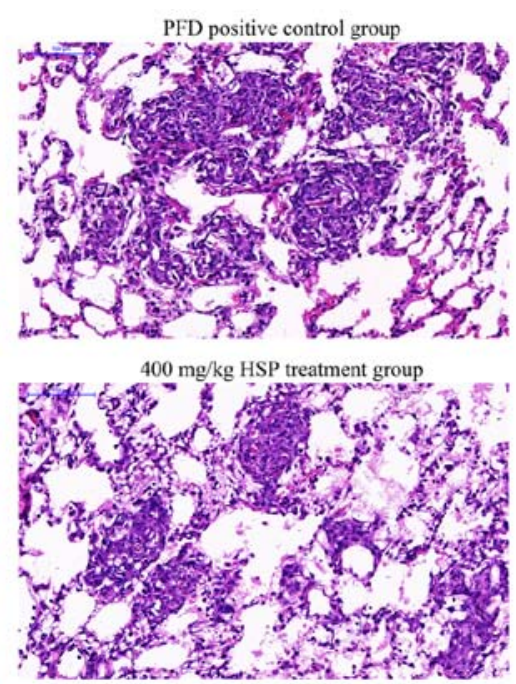

Figure 3. Hematoxylin and eosin staining of rat lung tissue on the 28th day (magnification, x200). The red arrows indicate inflammatory cells. Blue arrows indicate fibroblasts. HSP, hesperetin; PFD, pirfenidone.

of MDA in the silica model group was significantly higher compared with the negative control group $(\mathrm{P}<0.05)$. The level of MDA in the PFD and all HSP treatment groups was significantly decreased $(\mathrm{P}<0.05)$ compared with the silica model group (Fig. 8).

Effect of HSP on the activity of SOD and CAT in lung tissue of silica exposed rats. Compared with the negative control group, the SOD activity in the silica model group was markedly lower on the 7th day, but there was no statistical difference $(\mathrm{P}>0.05)$. However, the SOD activity in silica model group was significantly higher compared with the negative control group on the 28th day ( $\mathrm{P}<0.05$; Fig. 9A). Compared with the silica model group, no statistically significant difference in SOD activity was observed in the PFD and $100 \mathrm{mg} / \mathrm{kg} \mathrm{HSP}$ groups on the 28th day, but in the PFD and all the three dosages of HSP treatment group on the 7th day and 200 and $400 \mathrm{mg} / \mathrm{kg}$ HSP groups on the 28th day, the activity of SOD was significantly increased $(\mathrm{P}<0.05)$. There was no statistical difference in the CAT activity between the silica model group and the negative control group on the 7 and 28th days (P>0.05). Following treatment with 200 and $400 \mathrm{mg} / \mathrm{kg} \mathrm{HSP}$ on the 7th day and with all the three dosages of HSP on the 28th day, the activity of CAT significantly increased $(\mathrm{P}<0.05)$. On the contrary, in the PFD and $100 \mathrm{mg} / \mathrm{kg}$ HSP groups, the activity of CAT was markedly higher than the silica model group on the 7 th day, but there was no statistical difference (P>0.05; Fig. 9A and B).

Effect of HSP on the activity of GSH-Px and T-AOC in lung tissue of silica exposed rats. On the 7 and 28th days after exposure, there was no statistical difference in the activity of GSH-Px and T-AOC between silica model group and the negative control group ( $\mathrm{P}>0.05)$. After HSP treatment, it was revealed that GSH-Px activity in each group increased, and a significant difference was observed between the PFD 

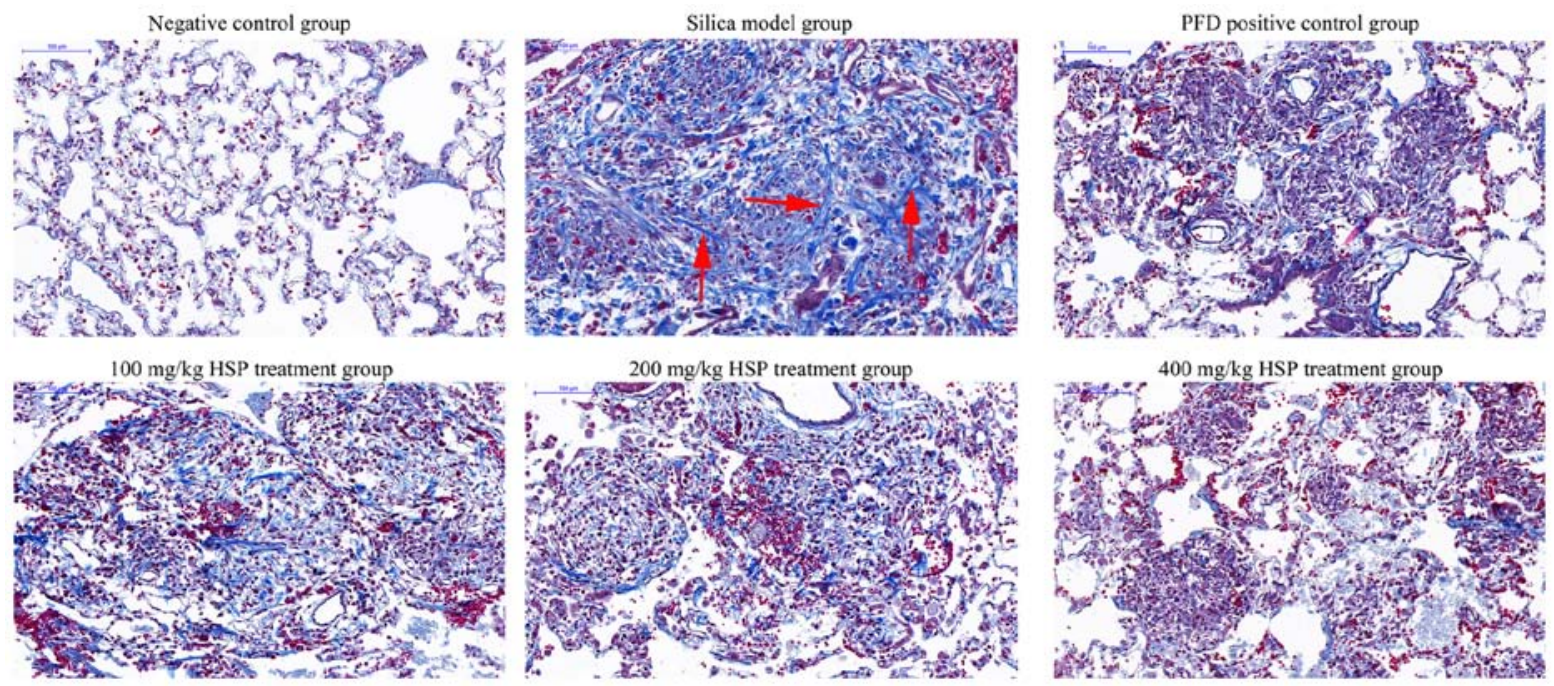

Figure 4. Masson's trichrome staining of rat lung tissue on the 28th day (magnification, x200). Red arrows indicate collagen. HSP, hesperetin; PFD, pirfenidone.

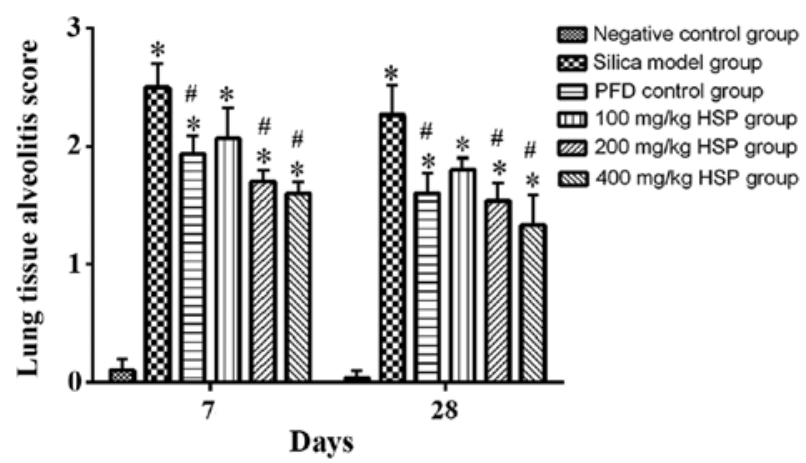

Figure 5. Effect of HSP treatment on the alveolar score in lung tissue of silica exposed rats on the 7 and 28 th days. ${ }^{*} \mathrm{P}<0.05$ vs. negative control group; ${ }^{\#} \mathrm{P}<0.05$ vs. silica model group. HSP, hesperetin; PFD, pirfenidone.

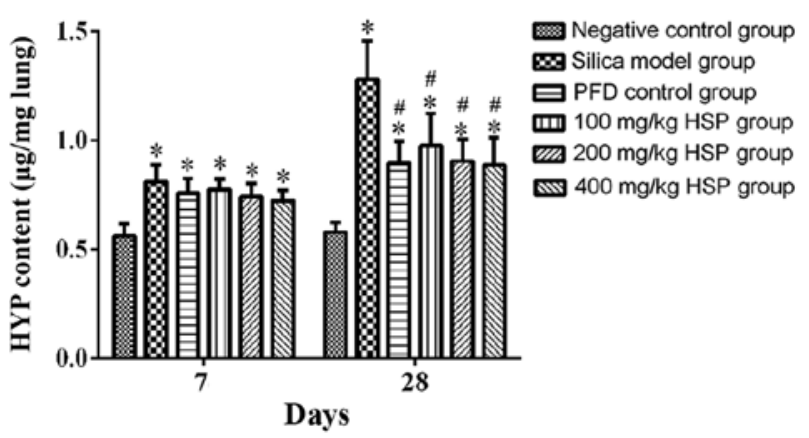

Figure 7. Effect of HSP treatment on the content of HYP in lung tissue of silica exposed rats on the 7 and 28 th days. ${ }^{*} \mathrm{P}<0.05$ vs. negative control group; ${ }^{\text {P }}<0.05$ vs. silica model group. HSP, hesperetin; PFD, pirfenidone; HYP, hydroxyproline.

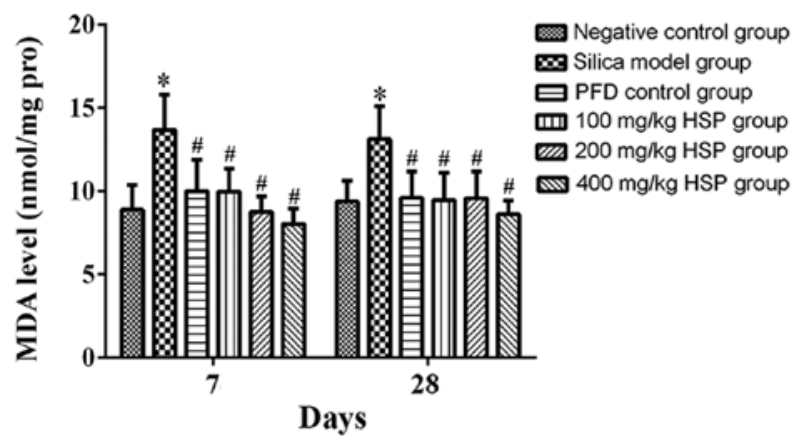

Figure 8. Expression of MDA. Effect of HSP treatment on the level of MDA in lung tissue of silica exposed rats on the 7 and 28 th days. ${ }^{*} \mathrm{P}<0.05$ vs. negative control group; " $\mathrm{P}<0.05$ vs. silica model group. HSP, hesperetin; PFD, pirfenidone; MDA, malondialdehyde; pro, protein.

day $(\mathrm{P}<0.05)$, while it was also increased in the PFD positive control group and 100 and $200 \mathrm{mg} / \mathrm{kg}$ HSP groups on the 28th day, but there was no statistical difference compared with the silica model group $(\mathrm{P}>0.05)$. In addition, compared with the model group, the T-AOC activity of the PFD positive control group and all the three dosages of HSP treatment group on the 7 th day was significantly increased $(\mathrm{P}<0.05$; Fig. $10 \mathrm{~A}$ and $\mathrm{B})$. in the $400 \mathrm{mg} / \mathrm{kg}$ HSP group was observed compared with the negative control group and silica model group on the 28th positive control group and the 200 and $400 \mathrm{mg} / \mathrm{kg}$ HSP groups compared with silica model group on the 7th day $(\mathrm{P}<0.05)$, but there was no statistical difference between the silica model group and the $100 \mathrm{mg} / \mathrm{kg}$ HSP group $(\mathrm{P}>0.05)$. It was clear that as the dose of HSP increased, the activity of GSH-Px also increased. An increasing trend of T-AOC levels 

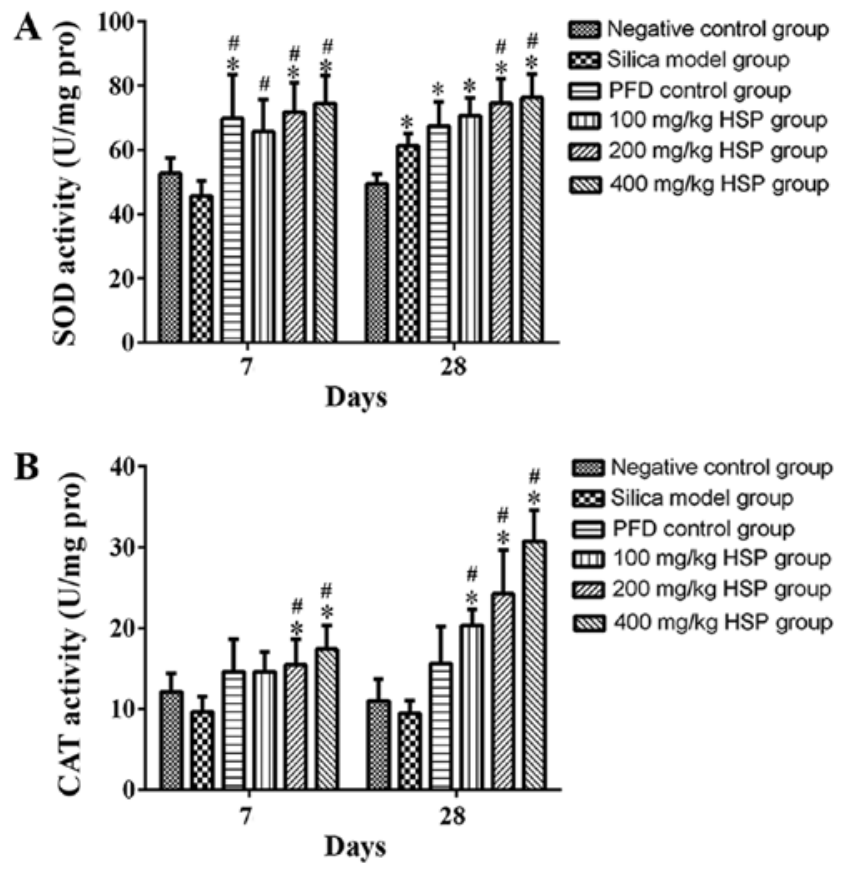

Figure 9. SOD and CAT activities. Effect of HSP on the activity of (A) SOD and (B) CAT in lung tissue of silica exposed rats on the 7 and 28th days. ${ }^{*} \mathrm{P}<0.05$ vs. negative control group; ${ }^{\#} \mathrm{P}<0.05$ vs. silica model group. HSP, hesperetin; PFD, pirfenidone; SOD, superoxide dismutase; CAT, catalase; pro, protein.

Analysis of TGF- $\beta 1, I L-1 \beta, I L-4, I L-10, T N F-\alpha$ and $I F N-\gamma$ levels in lung tissue

Effect of HSP on the levels of TGF- $\beta 1$ and IL-1 $\beta$ in lung tissue of silica exposed rats. On the 7 and 28th days after silica exposure, significantly higher levels of TGF- $\beta 1$ and IL- $1 \beta$ were observed in the silica model group compared with the negative control group (Fig. 11A and B). Compared with the silica model group, except for the $100 \mathrm{mg} / \mathrm{kg}$ HSP group on the 7 th day, after treatment with PFD and HSP, the level of TGF- $\beta 1$ was significantly lower compared with the silica model group $(\mathrm{P}<0.05)$. The level of IL-1 $\beta$ decreased on the 7 th day after treatment with PFD and HSP, but there was no statistical difference compared with the silica model group $(\mathrm{P}>0.05)$. On the 28th day, except for the $100 \mathrm{mg} / \mathrm{kg}$ HSP group, no significant difference was detected, and the levels of IL-1 $\beta$ in the PFD, 200 and $400 \mathrm{mg} / \mathrm{kg}$ groups were significantly reduced $(\mathrm{P}<0.05$; Fig. 11A and $\mathrm{B})$.

Effect of HSP on the levels of IL-4 and IL-10 in lung tissue of silica exposed rats. On the 7 and 28th days after silica exposure, the levels of IL-4 and IL-10 in the lung tissue of rats in the silica model group were significantly higher compared with the negative control group $(\mathrm{P}<0.05)$. On the 7 and 28th days after HSP treatment, the level of IL-4 decreased significantly, but there was only a statistical difference between the $400 \mathrm{mg} / \mathrm{kg}$ HSP group and the silica model group on the 28th day $(\mathrm{P}<0.05)$. Compared with silica model group, the levels of IL-10 in the $100 \mathrm{mg} / \mathrm{kg}$ HSP treatment group decreased on the 7 th day $(\mathrm{P}<0.05)$, but there were no significant differences in the PFD, 200 and $400 \mathrm{mg} / \mathrm{kg}$ HSP groups on the 7th day and in the PFD, 100 and $400 \mathrm{mg} / \mathrm{kg}$ HSP groups on the 28th day. ( $\mathrm{P}>0.05$; Fig. 12A and B).
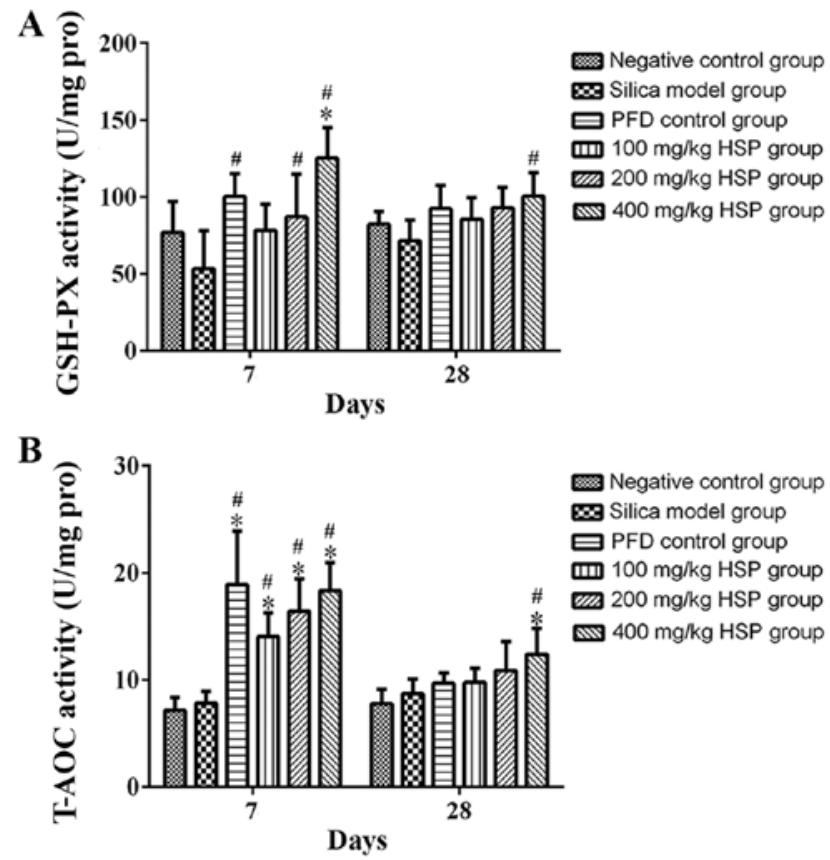

Figure 10. GSH-Px and T-AOC activities. Effect of HSP on the activity of (A) GSH-Px and (B) T-AOC in lung tissue of silica exposed rats on the 7 and 28 th days. ${ }^{*} \mathrm{P}<0.05$ vs. negative control group; ${ }^{\#} \mathrm{P}<0.05$ vs. silica model group. HSP, hesperetin; PFD, pirfenidone; GSH-Px, glutathione peroxidase; T-AOC, Total antioxidant capacity; pro, protein.

Effect of HSP on the levels of TNF- $\alpha$ and IFN- $\gamma$ in lung tissue of silica exposed rats. On the 7 and 28th days following silica exposure, the levels of TNF- $\alpha$ and IFN- $\gamma$ in lung tissue of rats in the silica model group was significantly higher compared with the negative control group $(\mathrm{P}<0.05)$. Following treatment with PFD and all HSP levels, the level of TNF- $\alpha$ was markedly lower compared with the silica model group. This was only significant in the high $(400 \mathrm{mg} / \mathrm{kg})$ dose group of HSP and the PFD group as compared with the silica model group $(\mathrm{P}<0.05)$ on the 28th day. Except for the $100 \mathrm{mg} / \mathrm{kg}$ HSP group on the 7th day, the IFN- $\gamma$ level of each treatment group was markedly higher compared with the silica model group, but there were no statistical differences observed $(\mathrm{P}>0.05)$. The general increases between the silica model and the treatment groups were markedly higher on the 28th day following silica exposure compared with the 7th day (Fig. 13A and B).

\section{Discussion}

The pathological characteristics of silica-induced pulmonary fibrosis at the primary stage include alveolitis, pulmonary edema and infiltration of inflammatory cells $(6,31)$. Developments of this disease include increased fibroblast proliferation and excessive collagen deposition leading to pulmonary fibrosis $(32,33)$. In the present study, two different time points in the animal model were used: Days 7 and 28 post-silica exposure. The 7th day following silica exposure represents the early inflammatory stage, and the 28th day represents the later fibrotic stage $(34,35)$. The aim of the current study was to demonstrate the pathological process of silica exposure. Oxidative stress and inflammatory response are considered to be two important mechanisms of silica-induced 

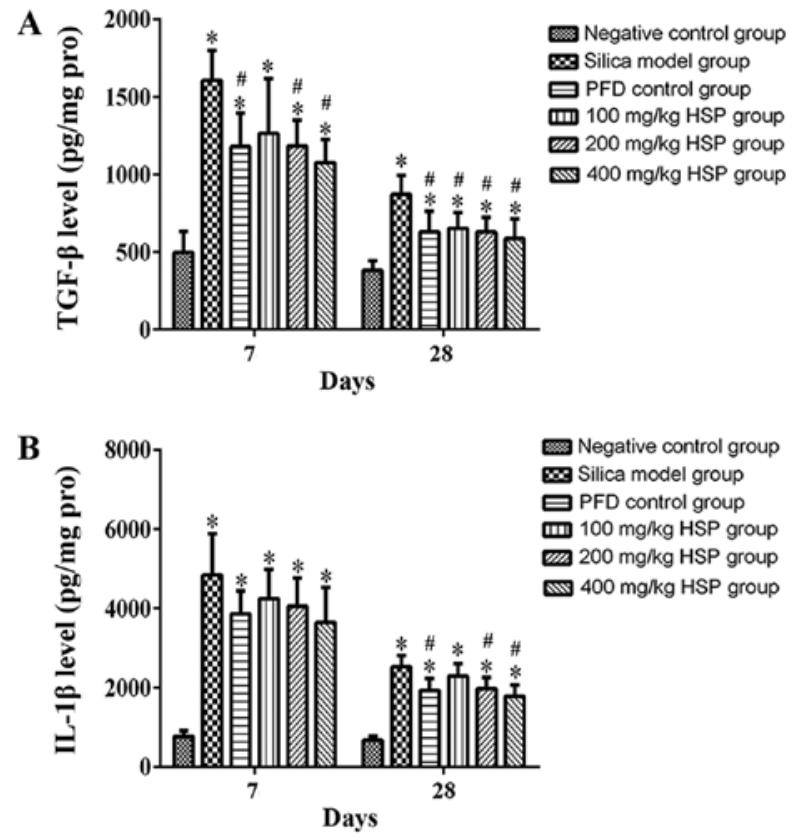

Figure 11. Expression of TGF- $\beta 1$ and IL-1 $\beta$. Effect of HSP on the levels of (A) TGF- $\beta 1$ and (B) IL-1 $\beta$ in lung tissue of silica exposed rats on the 7 and 28th days. ${ }^{*} \mathrm{P}<0.05$ vs. negative control group; ${ }^{*} \mathrm{P}<0.05$ vs. silica model group. HSP, hesperetin; PFD, pirfenidone; pro, protein.
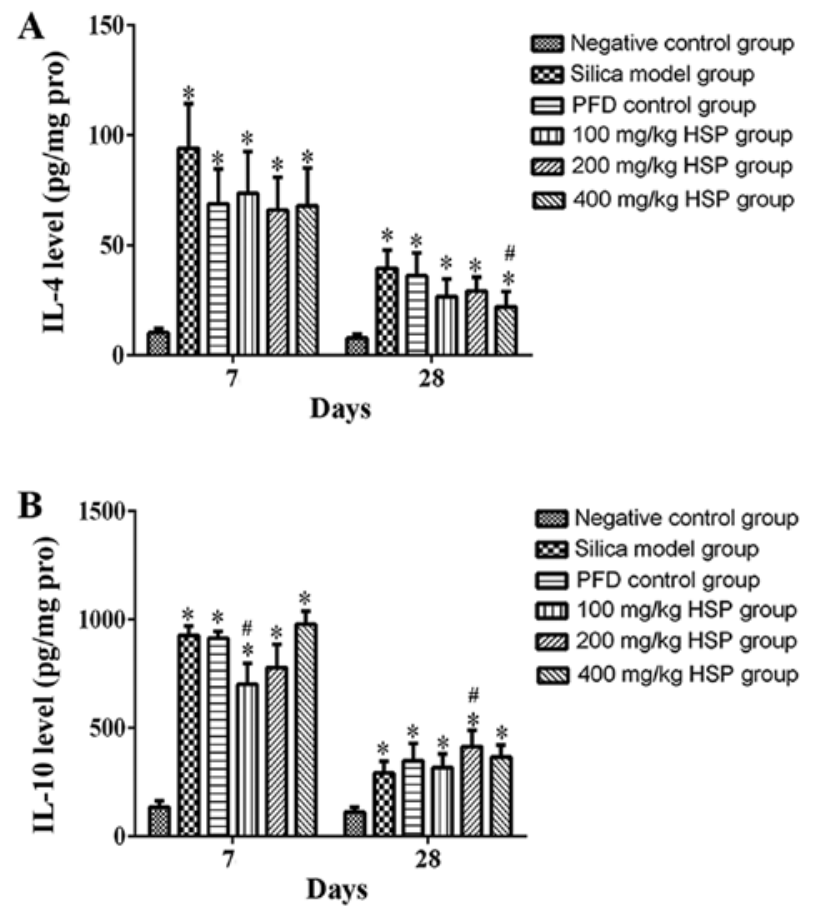

Figure 12. Expression of IL-4 and IL-10. Effect of HSP on the levels of (A) IL-4 and (B) IL-10 in lung tissue of silica exposed rats on the 7 and 28th days. ${ }^{\mathrm{P}}<0.05$ vs. negative control group; ${ }^{\#} \mathrm{P}<0.05$ vs. silica model group. HSP, hesperetin; PFD, pirfenidone; pro, protein.

lung injury (36). Oxidative stress can induce a inflammatory response by activating specific transcription factors, including $\mathrm{NF}-\mathrm{\kappa B}$ and Activator protein $1(37,38)$, and the inflammatory response in return exacerbates oxidative stress, contributing to excessive ROS generation in a number of different cell types following stimuli (9). An inflammatory response can
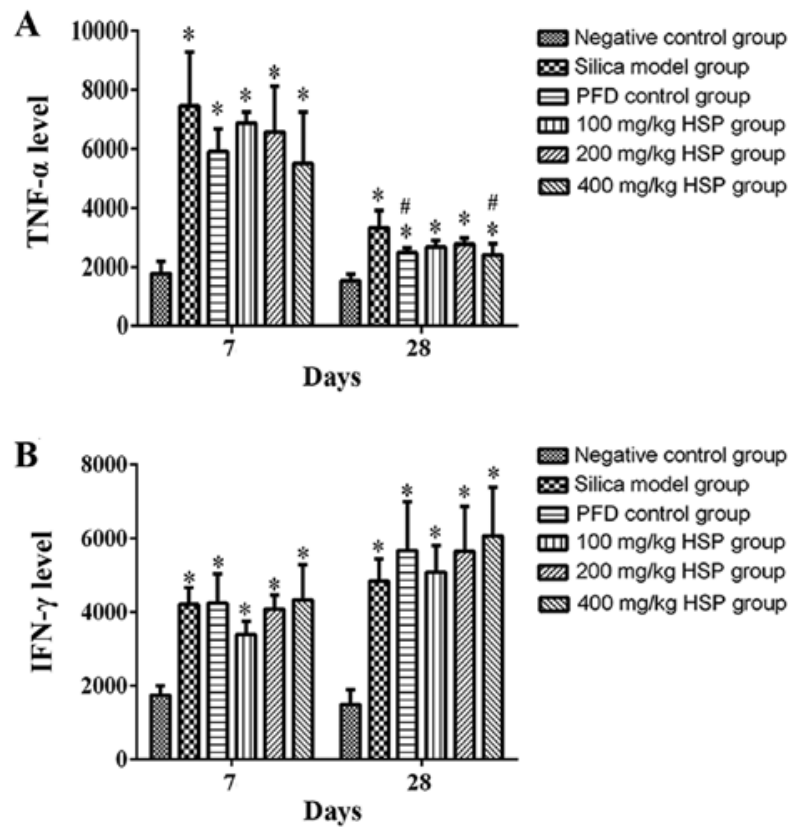

Figure 13. Expression of TNF- $\alpha$ and IFN- $\gamma$. Effect of HSP on the levels of (A) TNF- $\alpha$ and (B) IFN- $\gamma$ in lung tissue of silica exposed rats on the 7 and 28th days. ${ }^{*} \mathrm{P}<0.05$ vs. negative control group; ${ }^{\sharp} \mathrm{P}<0.05$ vs. silica model group. HSP, hesperetin; PFD, pirfenidone.

accelerate the progression of fibrosis through mast cells, which promote fibrosis by recruiting inflammatory cells to sites of damage (39). In the process of silica exposure, the cytokines interact and depend on each other to form a complex cytokine network that participates in the process of lung tissue injury (40). HYP is an amino acid that forms a major component of the protein collagen and is commonly used as a marker to measure the levels of collagen present (41). The results of the current study indicated that the content of HYP in rat lung tissues increased significantly following silica exposure. This was further increased in the fibrotic stage as compared to that during early inflammatory stage, which supports the observation that silica exposure leads to pulmonary fibrosis in rats. HSP treatment was shown to effectively reduce the content of HYP possibly by inhibiting the release of inflammatory factors to prevent the proliferation of fibroblasts. This is consistent with the histopathological findings of the current study.

As previously reported, when respirable crystalline silica particles are inhaled, they are able to reach the alveoli, inducing oxidative stress via the formation of ROS and nitrogen species $(42,43)$. MDA, which is a secondary product of lipid peroxidation, is a useful biomarker to evaluate oxidative stress (31). The current study demonstrated that the level of MDA in lung tissue significantly increased following 7 and 28 days of exposure to silica. SOD, CAT and GSH-Px are important antioxidant enzymes in cells and their activities can affect cellular capacity to scavenge free radicals and regulative oxidative stress (44). A previous study revealed that with a significant increase in lipid peroxidation in the venous blood samples, the activities of SOD and CAT were decreased in silicosis workers (45). In the present study, the activity of SOD was indicated to be markedly lower in lung tissue from rats in silica model group compared with the negative control group on the 7th day. However, activity of SOD increased in the silica 
model group compared with the negative control group on the 28th day. However, after treatment with different dosages of HSP, and especially with $400 \mathrm{mg} / \mathrm{kg} \mathrm{HSP}$, the activity of SOD increased compared with the model group. The present study also revealed that early invention using HSP was more effective on SOD activity during the early stage of lung injury compared with at the later stage of fibrosis. The results also demonstrated that the activity of CAT increased significantly in a dose-dependent manner following HSP treatment. This suggests that HSP inhibits oxidative damage by increasing the activity of antioxidant enzymes in the early stages of lung injury.

GSH is a major cellular antioxidant defense and serves an important role in scavenging free radicals and other ROS (46). Enhancing GSH and associated enzymes has previously been used as a therapeutic strategy for a number of different diseases including Alzheimer's disease, cancer, liver diseases, cardiovascular diseases, arthritis and diabetes (47-51). The current study indicated that silica-induced oxidative stress may result in the depletion of GSH, and the lack of GSH renders cells to be more susceptible to the effects of oxidants $(52,53)$. It was also revealed that silica decreased the activity of GSH-Px, which in turn aggravated lung toxicity. In the early stage of lung injury, it was clear that GSH-Px activity increased after treatment with 200 and $400 \mathrm{mg} / \mathrm{kg}$ doses of HSP. T-AOC is an index used to reflect the body's antioxidant capacity (54). The results of the present study indicated that the activity level of T-AOC in the HSP treatment group was significantly higher compared with the negative control group and silica model group on the 7th day of the model. This suggested that HSP was able to maintain the antioxidant capacity of the body at a high level. HSP has previously been considered to exhibit potent antioxidant activities. There has been previous evidence that HSP increases cellular antioxidant defense capacity via ERK/Nrf2 signaling and enhances the activity levels of antioxidant enzymes, such as CAT, SOD and GST in oxidative stress related-hepatocyte injury and liver dysfunction (55). HSP can also inhibit STZ-induced oxidative stress by increasing the activities of antioxidant enzymes (SOD, GSH-Px, GPX, GRX and CAT) and reducing the level of MDA in the hippocampus, providing evidence that it is of potential therapeutic value for Alzheimer's disease (56). The current study also demonstrated that HSP exhibits therapeutic potential for silica exposure via its strong antioxidant capacity.

In addition to oxidative stress, inflammation has been reported to be a contributing mechanism of lung injury (57). Under oxidative stress, immune cells are induced to produce and secrete inflammatory factors to stimulate inflammation, leading to pneumonia and fibrosis (58). At present, a number of studies have confirmed that a variety of cytokines are associated with the pathogenesis of silica exposure and these include TGF- $\beta 1$, IL- $1 \beta$ and TNF- $\alpha(59,60)$. TGF- $\beta 1$ serves an important role in the formation and development of pulmonary fibrosis, and acts as a stimulus signal in the repair of cell injury and the formation of fibrosis $(61,62)$. TGF- $\beta 1$ can induce and promote fibroblasts to transform into myofibroblasts, promote the precipitation of extracellular matrix, such as collagen, and inhibit its degradation (63). TGF- $\beta 1$ can also induce EMT of lung epithelial cells via the TGF- $\beta / \mathrm{Smad} 2$ signaling pathway (64). The results of the present study demonstrated that in the early injury stage of silica exposure, the level of TGF- $\beta 1$ in the silica model group was significantly higher compared with the negative control group. The inhibitory effect of HSP in each treatment group was more significant with increasing dosages, suggesting that HSP can inhibit the synthesis and secretion of fibrogenic factor TGF- $\beta 1$ in a dose-dependent manner. IL- $1 \beta$ and TNF- $\alpha$ are produced by macrophages as proinflammatory factors that can mediate the release of other cytokines and inflammatory mediators, thereby promoting the proliferation and differentiation of fibroblasts (65). In the current study, the levels of IL-1 $\beta$ and TNF- $\alpha$ increased following silica exposure, and the levels of these inflammatory factors decreased in the $400 \mathrm{mg} / \mathrm{kg}$ HSP group on the 28th day. Previous studies have also revealed that HSP can reduce the levels of TNF- $\alpha$ and IL-6, and protect TNBS-induced colitis model via its antioxidation, anti-inflammatory and anti-apoptotic effects (66). It is considered that HSP exhibits a protective effect on many diseases by exerting anti-inflammatory effects (67). Recent evidence has suggested the use of HSP derivatives to evaluate anti-inflammatory effects (68). IL-4 is a proinflammatory factor, which can antagonize IFN- $\gamma$ to promote the proliferation of fibroblasts, the production of extracellular matrix and increase the synthesis of collagen fibers (69-72). IFN- $\gamma$ is an effective anti-fibrotic factor due to its anti-proliferation and immunosuppressive effects in the regulation of inflammation $(73,74)$. IL-10, which is another anti-inflammatory cytokine, has been revealed to serve a role in blocking macrophage metabolism, promoting mitochondrial autophagy and inhibiting the synthesis of cytokines (75). IL-10 also exhibits an anti-fibrotic activity by reducing the production of type I collagen that is stimulated by TGF- $\beta(76,77)$. The results of the current study demonstrated that the level of IL-4 in the model group during the early injury stage was significantly higher compared with the negative control, PFD and all HSP treatment groups. Additionally, the levels of IL-10 and IFN- $\gamma$ in lung tissue of model group were markedly increased in the early injury stage, suggesting that they increased in a compensatory manner and inhibited the levels of inflammatory factors in lung tissue of early silica exposed rats following injury. After treatment with $400 \mathrm{mg} / \mathrm{kg} \mathrm{HSP}$ on the 28th day, the level of IL-4 decreased compared with the silica model group. During the late fibrotic stage (28th day), IFN- $\gamma$ levels in rat lung tissue increased compared with the model group, suggesting that PFD and HSP may serve an anti-fibrotic role by increasing IFN- $\gamma$ levels. Combined with the results of lung histopathology, it can be suggested that inflammatory factors serve a key role in the early stages of lung injury, and HSP may alleviate silica-induced lung injury in rats by reducing the level of inflammatory factors and increasing anti-inflammatory factors.

A previous report has been carried out on the treatment of silica-induced lung injury; however the treatment methods used are still not effective (78). PFD is an anti-fibrotic drug that is used clinically to treat mild to moderate IPF in a number of different countries (79). Recently, Zou et al (80) revealed that PFD could inhibit the expression of Wnt/ $\beta$-catenin signaling proteins and decrease the risk of lung cancer in patients with pulmonary fibrosis. A previous study has indicated that although PFD can reduce pulmonary fibrosis in rats with silica exposure, it cannot significantly increase their survival 
rate (81). However, PFD's mechanism of action remains largely unknown, and it is contraindicated in patients with severe hepatic injury and severe chronic renal failure (21). A previous clinical study has indicated that treatment of patients with this drug may bring about side effects associated with the gastrointestinal tract (nausea, emesis, abdominal discomfort, dyspepsia and diarrhea) and the skin (photosensitivity and rash) (21). Building on those previous studies, and in order to facilitate comparison, the current study established a PFD group as a positive control group to investigate the function of HSP. In recent years certain native compounds have been used to examine protective effect to silica-induced lung injury. For examples, previous studies have reported that HSP is a native compound derived from citrus fruit, which is reported to possess a number of different properties, including antitumor, antioxidant, anti-inflammatory and lipid lowering effects (82-84). Kumar et al (44) indicated that the therapeutic effects of HSP rectified retinal neuroinflammation, oxidative stress and oedema caused by chronic uncontrolled hyperglycaemic. Furthermore, HSP has been reported to be a potential anti-inflammatory and neuroprotective agent. A similar study has indicated that treatment with HSP can inhibit the NF- $\mathrm{B}$ and ERK signaling pathways through its antioxidant and anti-inflammatory activities, attenuating neuropathic pain that is induced by partial sciatic nerve ligation in rats (85). The current study demonstrated that HSP exhibits protective effects on lung injury in silica exposed rats via antioxidative and anti-inflammatory effects.

In conclusion, the results of the current study revealed that HSP can effectively inhibit the secretion of oxidative and inflammatory factors while increasing antioxidant and anti-inflammatory capacity to protect lung injury. According to the results of the present study, with increasing doses of HSP, the degree of lung injury gradually improved, and the medium $(200 \mathrm{mg} / \mathrm{kg})$ and high $(400 \mathrm{mg} / \mathrm{kg})$ doses of HSP were more effective in preventing lung injury. The current study provides a reliable pharmacological basis for the development and application of HSP in the future and as a potential therapeutic agent for the treatment of silicosis.

\section{Acknowledgements}

Not applicable.

\section{Funding}

The current study was supported by the Key Research and Development Plan of Shandong Province (grant no. 2016GSF201047), Shandong Traditional Chinese Medicine Science and Technology Development Plan Project (grant no. 2015-328), National Science Foundation of Shandong Province (grant no. ZR2019MH102), Science and Technology Development Plan of Jinan City (grant no. 201907061), and the Innovation Project of Shandong Academy of Medical Sciences.

\section{Availability of data and materials}

The datasets used and/or analyzed during the current study are available from the corresponding author on reasonable request.

\section{Authors' contributions}

GY and HS designed the study and confirmed the authenticity of the raw data. LS and SL performed the experiments and wrote the manuscript. JF, JZ and YC analyzed the data. AJY and MFL revised the manuscript critically for important intellectual content and were also involved in the conception of the study. All authors have read and approved the final manuscript.

\section{Ethics approval and consent to participate}

The current study was approved by the Ethics Committee of Shandong Academy of Occupational Health and Occupational Medicine (Jinan, China; approval no. 2018DL023).

\section{Patient consent for publication}

Not applicable.

\section{Competing interests}

The authors declare that they have no competing interests.

\section{References}

1. Bissonnette E and Rola-Pleszczynski M: Pulmonary inflammation and fibrosis in a murine model of asbestosis and silicosis. Possible role of tumor necrosis factor. Inflammation 13: 329-339, 1989.

2. Fubini B and Hubbard A: Reactive oxygen species (ROS) and reactive nitrogen species (RNS) generation by silica in inflammation and fibrosis. Free Radic Biol Med 34: 1507-1516, 2003.

3. Lopes-Pacheco M, Bandeira E and Morales MM: Cell-based therapy for silicosis. Stem Cells Int 2016: 5091838, 2016.

4. Chen JJ, Chen L, Liu W and Wang SX: Effects of Gymnadenia conopse alcohol extract on early protein profiles in lung tissue of rats exposed to silica. Zhonghua Lao Dong Wei Sheng Zhi Ye Bing Za Zhi 30: 432-435, 2012 (In Chinese).

5. Fernandez Alvarez R, Martinez Gonzalez C, Quero Martinez A, Blanco Perez JJ, Carazo Fernandez L and Prieto Fernandez A: Guidelines for the diagnosis and monitoring of silicosis. Arch Bronconeumol 51: 86-93, 2015

6. Rimal B, Greenberg AK and Rom WN: Basic pathogenetic mechanisms in silicosis: Current understanding. Curr Opin Pulm Med 11: 169-173, 2005.

7. Vallyathan V, Shi XL, Dalal NS, Irr W and Castranova V: Generation of free radicals from freshly fractured silica dust. Potential role in acute silica-induced lung injury. Am Rev Respir Dis 138: 1213-1219, 1988.

8. Ghio AJ, Kennedy TP, Whorton AR, Crumbliss AL, Hatch GE and Hoidal JR: Role of surface complexed iron in oxidant generation and lung inflammation induced by silicates. Am J Physiol 263: L511-L518, 1992.

9. Elmarakby AA and Sullivan JC: Relationship between oxidative stress and inflammatory cytokines in diabetic nephropathy. Cardiovasc Ther 30: 49-59, 2012.

10. Liu MW, Liu R, Wu HY, Li YY, Su MX, Dong MN, Zhang W and Qian CY: Radix puerariae extracts ameliorate paraquat-induced pulmonary fibrosis by attenuating follistatin-like 1 and nuclear factor erythroid 2p45-related factor-2 signalling pathways through downregulation of miRNA-21 expression. BMC Complement Altern Med 16: 11, 2016.

11. Hu HH, Chen DQ, Wang YN, Feng YL, Cao G, Vaziri ND and Zhao YY: New insights into TGF- $\beta /$ Smad signaling in tissue fibrosis. Chem Biol Interact 292: 76-83, 2018.

12. Borensztajn K, Crestani B and Kolb M: Idiopathic pulmonary fibrosis: From epithelial injury to biomarkers-insights from the bench side. Respiration 86: 441-452, 2013.

13. Kusaka T, Nakayama M, Nakamura K, Ishimiya M, Furusawa E and Ogasawara K: Effect of silica particle size on macrophage inflammatory responses. PLoS One 9: e92634, 2014. 
14. Wintergerst ES, Maggini S and Hornig DH: Contribution of selected vitamins and trace elements to immune function. Ann Nutr Metab 51: 301-323, 2007

15. Ribeiro D, Freitas M, Silva AMS, Carvalho F and Fernandes E: Antioxidant and pro-oxidant activities of carotenoids and their oxidation products. Food Chem Toxicol 120: 681-699, 2018.

16. Koleckar V, Kubikova K, Rehakova Z, Kuca K, Jun D, Jahodar L and Opletal L: Condensed and hydrolysable tannins as antioxidants influencing the health. Mini Rev Med Chem 8: 436-447, 2008.

17. Vitenberga $\mathrm{Z}$ and Pilmane $\mathrm{M}$ : Inflammatory, anti-inflammatory and regulatory cytokines in relatively healthy lung tissue as an essential part of the local immune system. Biomed Pap Med Fac Univ Palacky Olomouc Czech Repub 161: 164-173, 2017.

18. Joubert KD, Awori Hayanga J, Strollo DC, Lendermon EA, Yousem SA, Luketich JD, Ensor CR and Shigemura N: Outcomes after lung transplantation for patients with occupational lung diseases. Clin Transplant 33: e13460, 2019.

19. Amirshahrokhi K and Bohlooli S: Effect of methylsulfonylmethane on paraquat-induced acute lung and liver injury in mice. Inflammation 36: 1111-1121, 2013.

20. Sathiyamoorthy G, Sehgal S and Ashton RW: Pirfenidone and nintedanib for treatment of idiopathic pulmonary fibrosis. South Med J 110: 393-398, 2017

21. Meyer KC and Decker CA: Role of pirfenidone in the management of pulmonary fibrosis. Ther Clin Risk Manag 13: 427-437, 2017.

22. King TE Jr, Bradford WZ, Castro-Bernardini S, Fagan EA, Glaspole I, Glassberg MK, Gorina E, Hopkins PM, Kardatzke D, Lancaster L, et al: A phase 3 trial of pirfenidone in patients with idiopathic pulmonary fibrosis. N Engl J Med 370: 2083-2092, 2014.

23. Bahri S, Mies F, Ben Ali R, Mlika M, Jameleddine S, Entee KM and Shlyonsky V: Rosmarinic acid potentiates carnosic acid induced apoptosis in lung fibroblasts. PLoS One 12: e 0184368 , 2017.

24. Iranshahi M, Rezaee R, Parhiz H, Roohbakhsh A and Soltani F. Protective effects of flavonoids against microbes and toxins: The cases of hesperidin and hesperetin. Life Sci 137: 125-132, 2015.

25. MaH,Feng Xand Ding S: Hesperetin attenuates ventilator-induced acute lung injury through inhibition of NF-kB-mediated inflammation. Eur J Pharmacol 769: 333-341, 2015.

26. Roohbakhsh A, Parhiz H, Soltani F, Rezaee R and Iranshahi M: Molecular mechanisms behind the biological effects of hesperidin and hesperetin for the prevention of cancer and cardiovascular diseases. Life Sci 124: 64-74, 2015.

27. Bai X, Yang P, Zhou Q, Cai B, Buist-Homan M, Cheng H, Jiang J Shen D, Li L, Luo X, et al: The protective effect of the natura compound hesperetin against fulminant hepatitis in vivo and in vitro. Br J Pharmacol 174: 41-56, 2017.

28. Guide for the Care and Use of Laboratory Animals. 8th edition. National Academies Press, Washington, DC, 2011.

29. Szapiel SV, Elson NA, Fulmer JD, Hunninghake GW and Crystal RG: Bleomycin-induced interstitial pulmonary disease in the nude, athymic mouse. Am Rev Respir Dis 120: 893-899, 1979.

30. Yang YT, Zhang Y, Yu GC, Chen YJ, Bo CX, Jia Q and Shao H: Lung fibrosis and changes in autophagy-related proteins in rats exposed to silica dust. Zhonghua Lao Dong Wei Sheng Zhi Ye Bing Za Zhi 36: 890-895, 2018 (In Chinese).

31. Nardi J, Nascimento S, Goethel G, Gauer B, Sauer E, Fão N, Cestonaro L, Peruzzi C, Souza J and Garcia SC: Inflammatory and oxidative stress parameters as potential early biomarkers for silicosis. Clin Chim Acta 484: 305-313, 2018.

32. Castranova V and Vallyathan V: Silicosis and coal workers' pneumoconiosis. Environ Health Perspect 108 (Suppl 4): S675-S684, 2000.

33. Lapp NL and Castranova V: How silicosis and coal workers pneumoconiosis develop-a cellular assessment. Occup Med 8: 35-56, 1993.

34. Liu N, Cao F, Li Q, Zhang Y, Zhang Z and Guan W: Study of quercetin on pulmonary fibrosis by silica particles. Wei Sheng Yan Jiu 43: 814-818, 2014 (In Chinese).

35. Wang JY, Yu GC, Jia Q, Li C, Shao LL, Sai LL and Shao H: Preliminary analysis of differential expression of miRNA-423-5p and miRNA-26a-5p in lung tissue of early silicotic rats. Zhonghua Lao Dong Wei Sheng Zhi Ye Bing Za Zhi 37: 7-12, 2019 (In Chinese).

36. Zhao Y, Xu G, Li H, Chang M, Guan Y, Li Y, Wu W and Yao S: Overexpression of endogenous lipoic acid synthase attenuates pulmonary fibrosis induced by crystalline silica in mice. Toxicol Lett 323: 57-66, 2020
37. Hubbard AK, Thibodeau M and Giardina C: Cellular and molecular mechanisms regulating silica-induced adhesion molecule expression in mice. J Environ Pathol Toxicol Oncol 20 (Suppl 1): S45-S51, 2001

38. Hubbard AK, Timblin CR, Shukla A, Rincon M and Mossman BT: Activation of NF-kappaB-dependent gene expression by silica in lungs of luciferase reporter mice. Am J Physiol Lung Cell Mol Physiol 282: L968-L975, 2002.

39. Karlmark KR, Weiskirchen R, Zimmermann HW, Gassler N, Ginhoux F, Weber C, Merad M, Luedde T, Trautwein C and Tacke F: Hepatic recruitment of the inflammatory Grl+ monocyte subset upon liver injury promotes hepatic fibrosis Hepatology 50: 261-274, 2009.

40. Barrett EG, Johnston C, Oberdorster G and Finkelstein JN: Antioxidant treatment attenuates cytokine and chemokine levels in murine macrophages following silica exposure. Toxicol Appl Pharmacol 158: 211-220, 1999.

41. Kehrer JP, Lee YC and Solem SM: Comparison of in vitro and in vivo rates of collagen synthesis in normal and damaged lung tissue. Exp Lung Res 10: 187-201, 1986.

42. Cheresh P, Kim SJ, Tulasiram S and Kamp DW: Oxidative stress and pulmonary fibrosis. Biochim Biophys Acta 1832: 1028-1040, 2013

43. Vallyathan V, Mega JF, Shi X and Dalal NS: Enhanced generation of free radicals from phagocytes induced by mineral dusts. Am J Respir Cell Mol Biol 6: 404-413, 1992.

44. Kumar B, Gupta SK, Srinivasan BP, Nag TC, Srivastava S, Saxena R and Jha KA: Hesperetin rescues retinal oxidative stress, neuroinflammation and apoptosis in diabetic rats. Microvasc Res 87: 65-74, 2013

45. Anlar HG, Bacanli M, İritaş S, Bal C, Kurt T, Tutkun E, Yilmaz $\mathrm{OH}$ and Basaran N: Effects of occupational silica exposure on oxidative stress and immune system parameters in ceramic workers in Turkey. J Toxicol Environ Health A 80: 688-696, 2017

46. Pocernich CB and Butterfield DA: Elevation of glutathione as a therapeutic strategy in Alzheimer disease. Biochim Biophys Acta 1822: 625-630, 2012.

47. Peter C, Braidy N, Zarka M, Welch J and Bridge W: Therapeutic approaches to modulating glutathione levels as a pharmacological strategy in Alzheimer's disease. Curr Alzheimer Res 12: 298-313, 2015

48. Townsend DM, Tew KD and Tapiero H: The importance of glutathione in human disease. Biomed Pharmacother 57: 145-155, 2003.

49. Sacco R, Eggenhoffner R and Giacomelli L: Glutathione in the treatment of liver diseases: Insights from clinical practice. Minerva Gastroenterol Dietol 62: 316-324, 2016.

50. Nuttall SL, Martin U, Sinclair AJ and Kendall MJ: Glutathione: In sickness and in health. Lancet 351: 645-646, 1998.

51. Julius M, Lang CA, Gleiberman L, Harburg E, DiFranceisco W and Schork A: Glutathione and morbidity in a community-based sample of elderly. J Clin Epidemiol 47: 1021-1026, 1994

52. Karkale S, Khurana A, Saifi MA, Godugu C and Talla V: Oropharyngeal administration of silica in Swiss mice: A robust and reproducible model of occupational pulmonary fibrosis. Pulm Pharmacol Ther 51: 32-40, 2018.

53. Kliment CR and Oury TD: Oxidative stress, extracellular matrix targets, and idiopathic pulmonary fibrosis. Free Radic Biol Med 49: 707-717, 2010.

54. Wu FJ, Xue Y, Liu XF, Xue CH, Wang JF, Du L, Takahashi K and Wang YM: The protective effect of eicosapentaenoic acid-enriched phospholipids from sea cucumber Cucumaria frondosa on oxidative stress in PC12 cells and SAMP8 mice. Neurochem Int 64: 9-17, 2014.

55. Chen MC, Ye YY, Ji G and Liu JW: Hesperidin upregulates heme oxygenase-1 to attenuate hydrogen peroxide-induced cell damage in hepatic L02 cells. J Agric Food Chem 58: 3330-3335, 2010.

56. Kheradmand E, Hajizadeh Moghaddam A and Zare M: Neuroprotective effect of hesperetin and nano-hesperetin on recognition memory impairment and the elevated oxygen stress in rat model of Alzheimer's disease. Biomed Pharmacother 97 1096-1101, 2018

57. Rahman I and MacNee W: Oxidative stress and regulation of glutathione in lung inflammation. Eur Respir J 16: 534-554, 2000.

58. van der Vliet A, Janssen-Heininger YMW and Anathy V: Oxidative stress in chronic lung disease: From mitochondrial dysfunction to dysregulated redox signaling. Mol Aspects Med 63: 59-69, 2018

59. Dong X, Li X, Li M, Chen M, Fan Q and Wei W: Antiinflammation and antioxidant effects of thalidomide on pulmonary fibrosis in mice and human lung fibroblasts. Inflammation 40: 1836-1846, 2017. 
60. Kawasaki H: A mechanistic review of silica-induced inhalation toxicity. Inhal Toxicol 27: 363-377, 2015.

61. Bonner JC: Regulation of PDGF and its receptors in fibrotic diseases. Cytokine Growth Factor Rev 15: 255-273, 2004.

62. Phan SH: Genesis of the myofibroblast in lung injury and fibrosis. Proc Am Thorac Soc 9: 148-152, 2012.

63. Saito A and Nagase T: Hippo and TGF- $\beta$ interplay in the lung field. Am J Physiol Lung Cell Mol Physiol 309: L756-L767, 2015.

64. Zhu L, Fu X, Chen X, Han X and Dong P: M2 macrophages induce EMT through the TGF- $\beta /$ Smad2 signaling pathway. Cell Biol Int 41: 960-968, 2017.

65. Peteranderl C,Sznajder JI, Herold S and Lecuona E: Inflammatory responses regulating alveolar ion transport during pulmonary infections. Front Immunol 8: 446, 2017.

66. Polat FR, Karaboga I, Polat MS, Erboga Z, Yilmaz A and Guzel S: Effect of hesperetin on inflammatory and oxidative status in trinitrobenzene sulfonic acid-induced experimental colitis model. Cell Mol Biol (Noisy-le-grand) 64: 58-65, 2018.

67. Parhiz H, Roohbakhsh A, Soltani F, Rezaee R and Iranshahi M Antioxidant and anti-inflammatory properties of the citrus flavonoids hesperidin and hesperetin: An updated review of their molecular mechanisms and experimental models. Phytother Res 29: 323-331, 2015.

68. Huang AL, Zhang YL, Ding HW, Li B, Huang C, Meng XM and Li J: Design, synthesis and investigation of potential anti-inflammatory activity of O-alkyl and O-benzyl hesperetin derivatives. Int Immunopharmacol 61: 82-91, 2018.

69. Hashimoto S, Gon Y, Takeshita I, Maruoka S and Horie T: IL-4 and IL-13 induce myofibroblastic phenotype of human lung fibroblasts through c-Jun NH2-terminal kinase-dependent pathway. J Allergy Clin Immunol 107: 1001-1008, 2001

70. Postlethwaite AE, Holness MA, Katai H and Raghow R: Human fibroblasts synthesize elevated levels of extracellular matrix proteins in response to interleukin 4. J Clin Invest 90: 1479-1485, 1992.

71. Doucet C, Brouty-Boye D, Pottin-Clemenceau C, Jasmin C, Canonica GW and Azzarone B: IL-4 and IL-13 specifically increase adhesion molecule and inflammatory cytokine expression in human lung fibroblasts. Int Immunol 10: 1421-1433, 1998.

72. Doucet C, Brouty-Boye D, Pottin-Clemenceau C, Canonica GW, Jasmin C and Azzarone B: Interleukin (IL) 4 and IL-13 act on human lung fibroblasts. Implication in asthma. J Clin Invest 101: 2129-2139, 1998

73. Antoniou KM, Ferdoutsis E and Bouros D: Interferons and their application in the diseases of the lung. Chest 123: 209-216, 2003

74. Tzortzaki EG, Antoniou KM, Zervou MI, Lambiri I, Koutsopoulos A, Tzanakis N, Plataki M, Maltezakis G, Bouros D and Siafakas NM: Effects of antifibrotic agents on TGF-beta1, CTGF and IFN-gamma expression in patients with idiopathic pulmonary fibrosis. Respir Med 101: 1821-1829, 2007.
75. Ip WKE, Hoshi N, Shouval DS, Snapper S and Medzhitov R: Anti-inflammatory effect of IL-10 mediated by metabolic reprogramming of macrophages. Science 356: 513-519, 2017.

76. Cyktor JC, Carruthers B, Kominsky RA, Beamer GL, Stromberg P and Turner J: IL-10 inhibits mature fibrotic granuloma formation during Mycobacterium tuberculosis infection. J Immunol 190: 2778-2790, 2013.

77. Palomares O,Martin-FontechaM,LauenerR, Traidl-Hoffmann C, Cavkaytar O, Akdis M and Akdis CA: Regulatory T cells and immune regulation of allergic diseases: Roles of IL-10 and TGF- $\beta$. Genes Immun 15: 511-520, 2014.

78. Mlika M, Adigun R and Bhutta BS: Silicosis. In: StatPearls. StatPearls Publishing, Treasure Island, FL, 2020.

79. Xiao H, Zhang GF, Liao XP, Li XJ, Zhang J, Lin H, Chen Z and Zhang X: Anti-fibrotic effects of pirfenidone by interference with the hedgehog signalling pathway in patients with systemic sclerosis-associated interstitial lung disease. Int J Rheum Dis 21: 477-486, 2018

80. Zou WJ, Huang Z, Jiang TP, Shen YP, Zhao AS, Zhou S and Zhang S: Pirfenidone inhibits proliferation and promotes apoptosis of hepatocellular carcinoma cells by inhibiting the Wnt/ $\beta$-catenin signaling pathway. Med Sci Monit 23: 6107-6113, 2017.

81. Seifirad S, Keshavarz A, Taslimi S, Aran S, Abbasi H and Ghaffari A: Effect of pirfenidone on pulmonary fibrosis due to paraquat poisoning in rats. Clin Toxicol (Phila) 50: 754-758, 2012.

82. Chahar MK, Sharma N, Dobhal MP and Joshi YC: Flavonoids: A versatile source of anticancer drugs. Pharmacogn Rev 5: 1-12, 2011.

83. Wang J, Zhu H, Yang Z and Liu Z: Antioxidative effects of hesperetin against lead acetate-induced oxidative stress in rats. Indian J Pharmacol 45: 395-398, 2013.

84. Zhang J, Song J, Wu D, Wang J and Dong W: Hesperetin induces the apoptosis of hepatocellular carcinoma cells via mitochondrial pathway mediated by the increased intracellular reactive oxygen species, ATP and calcium. Med Oncol 32: 101, 2015.

85. Aswar M,Kute P,Mahajan S, Mahajan U, Nerurkar G and Aswar U: Protective effect of hesperetin in rat model of partial sciatic nerve ligation induced painful neuropathic pain: An evidence of anti-inflammatory and anti-oxidative activity. Pharmacol Biochem Behav 124: 101-107, 2014.

This work is licensed under a Creative Commons Attribution-NonCommercial-NoDerivatives 4.0 International (CC BY-NC-ND 4.0) License. 